\title{
Serum Vitamin D Level is Inversely Associated With Anti-Cyclic Citrullinated Peptide Antibody Level and Disease Activity in Rheumatoid Arthritis Patients
}

\author{
Yanan WANG, ${ }^{1}$ Fengwei ZHANG, ${ }^{2}$ Shanshan WANG, ${ }^{2}$ Xuechai SHANG, ${ }^{2}$ \\ Siyuna LUO, ${ }^{2}$ Hongjuan $\mathrm{ZHOU},{ }^{2}$ Huaping $\mathrm{SHI},{ }^{2}$ Long $\mathrm{CAI}^{2}$ \\ ${ }^{1}$ Clinical Laboratory, Yuhang District MCH Hospital, Hangzhou City, PR China \\ ${ }^{2}$ Laboratory of Rheumatism Department, Zhejiang TCM \& WM Hospital, Hangzhou City, PR China
}

\begin{abstract}
Objectives: This study aims to assess the relationship between serum vitamin D and anti-cyclic citrullinated peptide (anti-CCP) antibody levels, as well as disease activity in patients with newly diagnosed rheumatoid arthritis (RA).

Patients and methods: These measurements were conducted between January 2014 and June 2014. Serum 25-hydroxy vitamin D (25-OH-D), anti-CCP antibody, and erythrocyte sedimentation rates were measured in a cohort of 154 patients ( 66 males, 88 females; mean age $53.5 \pm 12.4$; range 29 to 79 years) with early RA. A control group of 60 healthy participants ( 25 males, 35 females; mean age $51.4 \pm 10.3$; range 25 to 75 years) was only evaluated for serum 25-OH-D levels. Disease activity was measured by calculating the 28-Joint Disease Activity Score. Blood samples were drawn from cubital veins. After centrifugation, serum was collected and stored under minus 20 degrees.

Results: Vitamin D deficiency was more prevalent in RA group compared with control group ( $48.70 \%$ vs. $30.00 \%$, p $<0.05)$. Serum $25-\mathrm{OH}-\mathrm{D}$ levels were lower in RA group $(19.46 \pm 8.20 \mathrm{ng} / \mathrm{mL})$ than control group $(23.18 \pm 6.71 \mathrm{ng} / \mathrm{mL})(p<0.05)$. In the RA group, serum $25-\mathrm{OH}-\mathrm{D}$ levels were negatively correlated to anti-CCP antibody levels $(r s=-0.360, p<0.001)$, erythrocyte sedimentation rate $(r s=-0.270, p<0.001)$, age of patients $(r s=-0.602$, $p<0.001)$, and disease activity ( $r s=-0.249, p<0.05)$, respectively. Serum $25-\mathrm{OH}-\mathrm{D}$ level did not vary according to sex in the RA group. In control group, females had lower serum $25-\mathrm{OH}-\mathrm{D}$ level $(\mathrm{p}=0.001, \mathrm{rs}=0.404)$. In addition, serum $25-\mathrm{OH}-\mathrm{D}$ level was also negatively associated with age in control group $(p<0.001, r s=-0.578)$. There were no differences between RA group and control group in terms of age and sex ratio.

Conclusion: Serum 25-OH-D level was negatively correlated to anti-CCP antibody level and disease activity, which implied the therapeutic role of serum 25-OH-D in RA.

Keywords: Anti-cyclic citrullinated peptide antibody; rheumatoid arthritis; vitamin D.
\end{abstract}

Rheumatoid arthritis (RA), which is characterized by joint pain, stiffness, and weakness that can lead to deformity and disability, commonly involve the hands and feet. It affects approximately 1\% of the population, with a female to male ratio of 3:1. ${ }^{1}$ The 2011 World report on disability found that nearly 11.9 million people worldwide have disability caused by RA. ${ }^{2}$ Anti-cyclic citrullinated peptide (anti-CCP) antibody is more reliable than rheumatoid factor in diagnosing RA. ${ }^{3}$ Anti-CCP test can accurately diagnose RA at a very early stage as compared to rheumatoid factor.

Vitamin D, which can be generated following ultraviolet light irradiation of the skin, is a secosteroid hormone involved in bone and calcium metabolism. It has long been recognized as an essential nutrient required for optimal absorption of dietary calcium and phosphate. Vitamin D deficiency is linked to development of bonesoftening diseases, such as rickets among children, 
and osteomalacia and osteoporosis among adults. Concerns on vitamin D's "non-classical" functions arose in the past decades. These non-classical functions include anticancer and cardiovascular actions, but prominent reports have also explored the association between vitamin D and the immune system. ${ }^{4}$ Recent studies have demonstrated that vitamin $\mathrm{D}$ deficiency correlates with the appearance of type 1 diabetes mellitus and multiple sclerosis. ${ }^{5}$ Vitamin D deficiency has been linked to a wider range of autoimmune conditions than multiple sclerosis and type 1 diabetes mellitus. ${ }^{6-8}$ It has been demonstrated recently that vitamin $\mathrm{D}$ deficiency is involved in the pathogenesis of RA, as well as activity of RA. ${ }^{9,10}$ In a meta-analysis, Song et al. ${ }^{9}$ found three studies amounting to 215,757 patients that involved vitamin $\mathrm{D}$ intake and the onset of RA. Of those 215,757 patients, 874 eventually developed RA. They found that individuals with the highest level of intake from food had a $24 \%$ lower risk of developing RA than those in the lowest group. However, another study did not show an association between vitamin $\mathrm{D}$ intake and the risk of RA. ${ }^{11}$ Thus, in this study, we aimed to assess the relationship between serum vitamin $\mathrm{D}$ and anti-CCP antibody levels, as well as disease activity in patients with newly diagnosed RA.

\section{PATIENTS AND METHODS}

The study subjects consisted of 154 patients (66 males, 88 females; mean age 53.5 \pm 12.4 ; range 29 to 79 years) with RA who admitted to Zhejiang TCM \& WM Hospital between January 2014 and June 2014. Patients eligible for the study were newly diagnosed RA patients with disease duration of less than one year and who had not been treated with non-steroidal anti-inflammatory drugs prior to our study. Patients with endocrine disease were excluded. All patients fulfilled the 2010 American College of Rheumatology/ European League Against Rheumatism RA classification criteria. ${ }^{12}$ Meanwhile, a control group of 60 healthy subjects (25 males, 35 females; mean age $51.4 \pm 10.3$; range 25 to 75 years) was investigated. Participants in this study did not receive vitamin D supplements. All procedures were in accordance with the ethical standards of the responsible committee on human experimentation and the Helsinki Declaration.
In the RA group; serum 25-hydroxy vitamin D (25-OH-D), anti-CCP antibody levels, and erythrocyte sedimentation rate (ESR) were measured, respectively. Only serum 25-OH-D levels were measured in the control group. Blood samples were drawn from cubital veins and fed into the collection tube. After centrifugation, serum was collected and stored under minus 20 degrees.

Serum 25-OH-D levels were measured in the clinical laboratory by an automated electrochemiluminescent immunoassay from Roche Diagnostics. The sensitivity of the assay was less than $3.0 \mathrm{ng} / \mathrm{mL}$. The recovery was approximately $100 \%$ for 25-OH-D. Within and between batch precision was less than $7.5 \%$ and less than $13.6 \%$, respectively. Vitamin D status was defined as follows: $\geq 30 \mathrm{ng} / \mathrm{mL}$, sufficiency; $\geq 21 \mathrm{ng} / \mathrm{mL}, \quad<29 \mathrm{ng} / \mathrm{mL}$, insufficiency; $\leq 20 \mathrm{ng} / \mathrm{mL}$, deficiency. ${ }^{13,14}$ Anti-CCP antibody assays were performed at our hospital in the Rheumatology Clinical Research Laboratory using a CCP ELISA kit (Shanghai Kexin Biotech Co., Ltd., Shanghai, China) according to the manufacturer's instructions. For anti-CCP testing, a level of $\geq 25$ relative units $(\mathrm{RU}) / \mathrm{mL}$ was considered positive.

Disease activity was evaluated by calculating the 28-Joint Disease Activity Score (DAS28), as well as the Health Assessment Questionnaire index and visual analog scale (VAS) pain score, according to the formula on the DAS website. ${ }^{15}$ According to disease activity, RA group patients were divided into four sub-groups as follows: $>5.1$ : high disease activity (grade 4, abbreviated as G4), $>3.2$ - $\leq 5.1$ : moderate disease activity (grade 3 , abbreviated as G3); $\leq 3.2$ : low disease activity (grade 2, abbreviated as G2), and <2.6: very low disease activity (grade 1 , abbreviated as G1).

\section{Statistical analysis}

Statistical analysis was performed using the statistical package for Windows IBM SPSS version 19.0 (IBM Corporation, Armonk, NY, USA). Quantitative data were expressed as mean \pm standard deviation. Qualitative data were expressed as frequency and percent. Student's t-test was used to compare quantitative data of two groups (normality test had been performed). Chi square test was used for qualitative data analysis. Multiple linear regression was performed 
Table 1. Clinical characteristics of rheumatoid arthritis and control groups

\begin{tabular}{|c|c|c|c|c|c|c|c|}
\hline & \multicolumn{6}{|c|}{ Subjects } & \multirow[b]{3}{*}{$p$} \\
\hline & \multicolumn{3}{|c|}{ RA group ( $\mathrm{n}=154)$} & \multicolumn{3}{|c|}{ Control group $(n=60)$} & \\
\hline & $\mathrm{n}$ & $\%$ & Mean \pm SD & $\mathrm{n}$ & $\%$ & Mean \pm SD & \\
\hline Age (years) & & & $53.5 \pm 12.4$ & & & $51.4 \pm 10.3$ & 0.240 \\
\hline Gender & & & & & & & 0.875 \\
\hline Female & 88 & & & 35 & & & \\
\hline Male & 66 & & & 25 & & & \\
\hline Serum 25-OH-D level (ng/mL) & & & $19.5 \pm 8.2$ & & & $23.2 \pm 6.7$ & 0.001 \\
\hline Deficiency ratio & & 48.70 & & & 30.00 & & 0.013 \\
\hline Insufficiency ratio & & 36.36 & & & 48.33 & & 0.108 \\
\hline Sufficiency ratio & & 14.94 & & & 21.67 & & 0.237 \\
\hline
\end{tabular}

to analyze the relationship between indices of disease activity and serum 25-OH-D levels. One-way ANOVA was used to compare the differences between different sub-groups in RA group. Least-significant difference test was used for multiple comparisons. A $p$ value less than 0.05 was considered statistically significant.

\section{RESULTS}

Clinical characteristics of study participants are presented in Table 1. There were no differences between RA and control groups according to age and sex ratio. Compared with the control group, the level of serum 25-OH-D in RA patients was lower $(19.46 \pm 8.20$ vs. $23.18 \pm 6.71$, $\mathrm{p}=0.001$ ). Moreover, vitamin $\mathrm{D}$ deficiency was more prevalent in RA group compared with control group $(48.70 \%$ vs. $30.00 \%, p=0.013)$. In RA patients, correlation coefficients of some variables with vitamin $\mathrm{D}$ serum level were presented in Table 2. The correlation coefficient of serum 25-OH-D for DAS28 was -0.249 using the multiple linear regression, which indicated that there is an inverse relationship between serum 25-OH-D levels and severity of RA $(p=0.001)$. In addition, serum 25-OH-D levels were higher in the first three stages of RA (G1, G2, G3) compared with the fourth stage (G4), while the statistical data of age, ESR, and anti-CCP antibody in different stages showed an opposite tendency (Figure 1). This finding suggested that more severe cases of RA were accompanied by lower serum 25-OH-D levels $(\mathrm{p}<0.05)$, and higher ESR levels and anti-CCP antibody levels $(p<0.01, p<0.05$, respectively) (Figure 1). The mean age of RA patients was $53.51 \pm 12.38$ (median 54.5) and correlation coefficient between age and serum 25-OH-D was -0.602 , which showed that the older patients had the lower serum 25-OH-D level $(p<0.001)$ (Table 2). The average number of joints with tenderness was $1.51 \pm 1.518$ (median 2) and correlation coefficient associated with serum $25-\mathrm{OH}-\mathrm{D}$ level was -0.154 , which indicated that there is an inverse relationship between serum $25-\mathrm{OH}-\mathrm{D}$ levels and the number of tender joints

Table 2. Correlation coefficient of some variables with serum 25-OH-D levels within rheumatoid arthritis group

\begin{tabular}{lccrr}
\hline Variables & Mean \pm SD & Median & Estimated coefficient & $p$ \\
\hline Age (years) & $53.5 \pm 12.38$ & 54.5 & -0.602 & $<0.001$ \\
Gender & - & - & 0.020 & 0.403 \\
Disease activity score in 28 joints & $3.42 \pm 1.05$ & 3.18 & -0.249 & 0.001 \\
Tender joint (no.) & $1.51 \pm 1.518$ & 2 & -0.154 & 0.028 \\
Swollen joint (no.) & $2.74 \pm 1.98$ & 1 & -0.068 & 0.203 \\
Visual analog scale & $25.58 \pm 14.21$ & 25 & -0.105 & 0.097 \\
Erythrocyte sedimentation rate & $25.14 \pm 24.31$ & 16 & -0.270 & $<0.001$ \\
Anti-cyclic citrullinated peptide antibody & $740.54 \pm 715.45$ & 542.95 & -0.360 & $<0.001$ \\
\hline 25-OH-D: 25-hydroxyvitamin D; SD: Standard deviation; Multiple linear regression was used for data analysis. & & \\
\hline
\end{tabular}



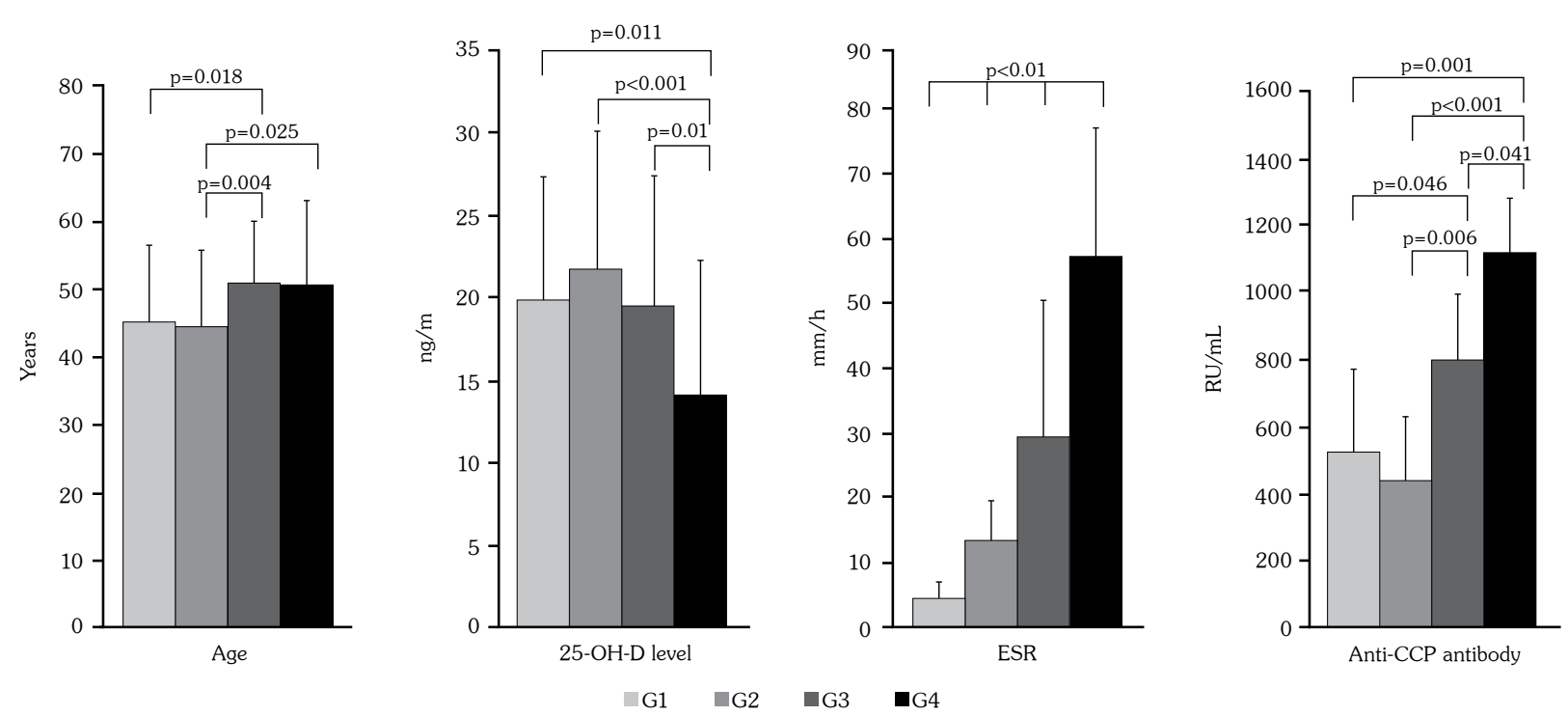

Figure 1. Differences between some variables among subgroups of group RA. Differences of age, serum 25-OH-D levels, ESR and anti-CCP antibody levels among subgroups. Group RA $(n=154)$ were regrouped by disease grade as above: grade 1, grade 2, grade 3 and grade 4, which are abbreviated as G1, G2, G3 and G4, respectively. 25-OH-D: 25-hydroxy vitamin D; ESR: Erythrocyte sedimentation rate; RU: Relative units; CCP: Cyclic citrullinated peptide; RA: Rheumatoid arthritis.

$(\mathrm{p}=0.020)$. The mean ESR was $25.14 \pm 24.31$ (median 16) and the mean anti-CCP antibody level was 740.54 \pm 715.45 (median 542.95). The correlation coefficient of serum 25-OH-D level for ESR and anti-CCP antibody level were -0.270 and -0.360 , respectively. This showed that serum 25-OH-D level is also related to ESR $(p<0.001)$ or anti-CCP antibody level $(p<0.001)$. However, we did not find any relationship between serum 25-OH-D level and VAS or swollen joint number ( $p=0.301, p=0.098$, respectively). Serum 25-OH-D level did not vary according to sex in the RA group. On the contrary, the difference of serum 25-OH-D levels between the sexes was significant in control group which indicated that the females had lower serum 25-OH-D level $(p=0.001, r s=0.404)$ (Table 3). In control group, the relationship between age and serum $25-\mathrm{OH}-$ $\mathrm{D}$ level was roughly in line with the trend seen in RA group $(p<0.001, r s=-0.578)$ (Table 3$)$.

\section{DISCUSSION}

In this study, while we found an inverse association between the level of serum $25-\mathrm{OH}-$ $\mathrm{D}$ and DAS28, age of patients, the number of tender joints, ESR, and anti-CCP antibody level, no relationship was detected between the serum 25-OH-D level and VAS or the number of swollen joints. Moreover, compared with the age and sex matched control group, the level of serum 25-OH-D in RA patients was much lower.

Our findings are significantly similar with those of a study conducted by Patel et al. ${ }^{16}$ which covered 309 patients with inflammatory polyarthritis for less than four months. In that study, vitamin D level was lower in patients experiencing more disease activity at the early stage and after one year of follow-up and the incidence of RA was higher among the individuals with lower serum vitamin D levels.

Table 3. Correlation coefficient of gender or age with serum 25-OH-D levels within control group

\begin{tabular}{lcccr}
\hline Variables & Mean \pm SD & Median & Estimated coefficient & $p$ \\
\hline Age (years) & $51.38 \pm 10.34$ & 52.5 & -0.578 & $<0.001$ \\
Gender & - & - & 0.404 & 0.001 \\
\hline 25-OH-D: 25-hydroxyvitamin D; SD: Standard deviation; Multiple linear regression was used for data analysis. & & \\
\hline
\end{tabular}


These patients had lower Health Assessment Questionnaire levels and more tender joints. In Abourazzak's study, ${ }^{8}$ serum 25-OH-D concentration was inversely associated with DAS, VAS, and number of tender joints. Their study also showed an inverse relationship between serum 25-OH-D level and the number of swollen joints, but this finding was not supported by our study. A meta-analysis of 215,757 participants and 874 RA cases showed an association between total vitamin $\mathrm{D}$ intake and RA incidence without between-study heterogeneity. ${ }^{9}$ Individuals in the highest group for total vitamin $\mathrm{D}$ intake were found to have a lower risk of developing RA than those in the lowest group. Furthermore, available evidence in this study indicates that vitamin $\mathrm{D}$ level is associated with RA activity. Pincus and Sokka' study $^{17}$ also showed an inverse relationship between ESR and serum vitamin D levels; however, this finding was not consistent with the results of a study by Zakeri et al., ${ }^{18}$ which also revealed a reverse relationship between serum 25-OH-D level and number of swollen joints.

In our study, about $48.7 \%$ of RA patients had vitamin $\mathrm{D}$ deficiency. In a recent study, the prevalence of vitamin $\mathrm{D}$ deficiency was reported to be about 51.9\%. ${ }^{19}$ In another study in Isfahan, this rate was reported to be about $50.8 \% .^{20}$ Another study in the United States investigated $62 \mathrm{RA}$ patients in terms of vitamin D and DAS28 levels and showed that about 61\% of patients had low vitamin $\mathrm{D}$ levels (less than $30 \mathrm{ng} / \mathrm{mL}$ ). An inverse relationship was also found between vitamin $\mathrm{D}$ level and high disease activity (DAS28 >2.6), while the relationship between the vitamin $\mathrm{D}$ level and controlled disease (DAS28 <2.6) was not significant. These results confirm correlation between high and moderate activity of disease and vitamin $\mathrm{D}$ levels. ${ }^{21}$ In our study, results were significant between highest level of disease activity and the other levels.

Recent studies have focused on the immunologic activity of Vitamin D which is independent of its classical role in calcium regulation. ${ }^{22-25}$ Animal models of autoimmune disease have shown beneficial effects of vitamin $\mathrm{D}$ as an immunosuppressant. Cantorna et al. $^{23}$ suggested that active vitamin $\mathrm{D}$ can be used to decrease incidence and severity of disease in murine models of human RA. Target cell responses to vitamin $\mathrm{D}$ are dependent on expression of the intracellular vitamin $\mathrm{D}$ receptor (VDR). When tumor necrosis factor transgenic mice are interbred with VDR deficient mice, the VDR deficient tumor necrosis factor transgenic mice have earlier onset of a more aggressive chronic arthritis, suggesting that signaling via a VDR is implicated in the pathogenesis of arthritis. ${ }^{25}$ A recent study showed significant differences between patients and healthy controls in the frequency of BsmI and TaqI, suggesting BsmI and TaqI polymorphisms may be susceptibility risk factors for RA. ${ }^{25}$ These studies suggested that vitamin $\mathrm{D}$ function in RA may also be dependent on its VDR expression level on the target cells or VDR polymorphisms. The relationship between serum vitamin $\mathrm{D}$ level and RA disease are more complex than we think.

Our study was based on a broad sample prospective design and rigorous case validation. We demonstrated negatively correlated serum 25-OH-D levels to the anti-CCP antibody levels and disease activity. Anti-CCP antibodies are used as highly specific and sensitive markers in the diagnosis and severity evaluation of RA. Therefore, anti-CCP antibody level can be used as an indicator for supplementation treatment of vitamin D in the early RA. In Sahebari's study, ${ }^{26}$ anti-CCP antibodies were shown to have no correlation with serum 25-OH-D in chronic patients. However, they found that the antiCCP levels and serum 25-OH-D values showed a negative correlation with serum 25-OH-D in new cases, which was in line with our findings. They also found no correlation between serum 25-OH-D serum levels and DAS score. Their study included patients under treatment with supplementary calcium carbonate, serum 25-OH-D, and hydroxychloroquine. Our participants consisting of healthy subjects and patients with very recently diagnosed RA were not under any supplementary treatment. We believe that this was the primary reason why our outcomes were different from others in terms of the relationships between serum 25-OH-D and anti-CCP antibody levels or DAS28 scores.

Nonetheless, there are some limitations to this study in answering the question whether low vitamin $\mathrm{D}$ is a motivation factor or consequential 
for RA activity. Hong et al. ${ }^{27}$ found that serum 25-OH-D levels were reduced in patients with RA and negatively associated with disease activity, interleukin 17/interleukin 23, and bone loss in $\mathrm{RA}$, suggesting that vitamin $\mathrm{D}$ deficiency may play a role in the etiology of RA. We also showed negatively correlated serum 25-OH-D levels to the anti-CCP antibody and ESR levels, and disease activity. Furthermore, greater intake of vitamin D can lower the risk of RA. ${ }^{9}$ In conclusion, it seems that low vitamin $\mathrm{D}$ level is a motivation factor rather than a consequence of RA activity. Serum 25-OH-D level was negatively correlated to antiCCP antibody level and disease activity, which implied the therapeutic role of serum 25-OH-D in RA. Still, further studies on the pathogenesis of RA involving vitamin $\mathrm{D}$ are required.

\section{Declaration of conflicting interests}

The authors declared no conflicts of interest with respect to the authorship and/or publication of this article.

\section{Funding}

This work was supported by grants from The Intramural Research Start-up Fund of Zhejiang TCM \& WM Hospital and Science and Technology Plan Projects of Zhejiang Medicine and Health Program (2014KYA184).

\section{REFERENCES}

1. World Health Organization. Principles and methods for assessing autoimmunity associated with exposure to chemicals; 2006.

2. World Health Organization. World report on disability. 2011.

3. Nikolaisen C, Rekvig OP, Nossent HC. Diagnostic impact of contemporary biomarker assays for rheumatoid arthritis. Scand J Rheumatol 2007;36:97-100.

4. Hewison M. Vitamin D and immune function: an overview. Proc Nutr Soc 2012;71:50-61.

5. Jankosky C, Deussing E, Gibson RL, Haverkos HW. Viruses and vitamin D in the etiology of type 1 diabetes mellitus and multiple sclerosis. Virus Res 2012;163:424-30.

6. Yap KS, Morand EF. Vitamin D and systemic lupus erythematosus: continued evolution. Int $\mathrm{J}$ Rheum Dis 2015;18:242-9.

7. Bizzaro G, Shoenfeld Y. Vitamin D and autoimmune thyroid diseases: facts and unresolved questions. Immunol Res 2015;61:46-52.
8. Abourazzak FE, Talbi S, Aradoini N, Berrada K, Keita S, Hazry T. 25-Hydroxy vitamin D and its relationship with clinical and laboratory parameters in patients with rheumatoid arthritis. Clin Rheumatol 2015;34:353-7.

9. Song GG, Bae SC, Lee YH. Association between vitamin $\mathrm{D}$ intake and the risk of rheumatoid arthritis: a meta-analysis. Clin Rheumatol 2012;31:1733-9.

10. Kim TH, Choi SJ, Lee YH, Song GG, Ji JD. Combined therapeutic application of mTOR inhibitor and vitamin $\mathrm{D}$ (3) for inflammatory bone destruction of rheumatoid arthritis. Med Hypotheses 2012;79:757-60.

11. Baker JF, Baker DG, Toedter G, Shults J, Von Feldt JM, Leonard MB. Associations between vitamin $\mathrm{D}$, disease activity, and clinical response to therapy in rheumatoid arthritis. Clin Exp Rheumatol 2012;30:658-64.

12. Aletaha D, Neogi T, Silman AJ, Funovits J, Felson DT, Bingham CO, et al. 2010 Rheumatoid arthritis classification criteria: an American College of Rheumatology/European League Against Rheumatism collaborative initiative. Arthritis Rheum 2010;62:2569-81.

13. Dawson-Hughes B, Heaney RP, Holick MF, Lips P, Meunier PJ, Vieth R. Estimates of optimal vitamin D status. Osteoporos Int 2005;16:713-6.

14. Souberbielle JC, Body JJ, Lappe JM, Plebani M, Shoenfeld Y, Wang TJ, et al. Vitamin D and musculoskeletal health, cardiovascular disease, autoimmunity and cancer: Recommendations for clinical practice. Autoimmun Rev 2010;9:709-15.

15. DAS28. Home of the DAS: Disease activity score in rheumatoid arthritis; 2015.

16. Patel S, Farragher T, Berry J, Bunn D, Silman A, Symmons D. Association between serum vitamin D metabolite levels and disease activity in patients with early inflammatory polyarthritis. Arthritis Rheum 2007;56:2143-9.

17. Pincus T, Sokka T. Laboratory tests to assess patients with rheumatoid arthritis: advantages and limitations. Rheum Dis Clin North Am 2009;35:731-4.

18. Zakeri Z, Sandoughi M, Mashhadi MA, Raeesi V, Shahbakhsh S. Serum vitamin D level and disease activity in patients with recent onset rheumatoid arthritis. Int J Rheum Dis 2013 Oct 18. [Epub ahead of print]

19. Dehghan A, Rahimpour S, Soleymani-Salehabadi $\mathrm{H}$, Owlia MB. Role of vitamin D in flare ups of rheumatoid arthritis. Z Rheumatol 2014;73:461-4.

20. Hovsepian S, Amini M, Aminorroaya A, Amini P, Iraj B. Prevalence of vitamin D deficiency among adult population of Isfahan City, Iran. J Health Popul Nutr 2011;29:149-55.

21. Haque UJ, Bartlett SJ. Relationships among vitamin $\mathrm{D}$, disease activity, pain and disability in rheumatoid arthritis. Clin Exp Rheumatol 2010;28:745-7.

22. Hewison M. Vitamin D and immune function: an overview. Proc Nutr Soc 2012;71:50-61. 
23. Cantorna MT, Hayes CE, DeLuca HF. 1,25-Dihydroxycholecalciferol inhibits the progression of arthritis in murine models of human arthritis. $\mathrm{J}$ Nutr 1998;128:68-72.

24. Zwerina K, Baum W, Axmann R, Heiland GR, Distler JH, Smolen J, et al. Vitamin D receptor regulates TNF-mediated arthritis. Ann Rheum Dis 2011;70:1122-9.

25. Mosaad YM, Hammad EM, Fawzy Z, Abdal Aal IA, Youssef HM, ElSaid TO, et al. Vitamin D receptor gene polymorphism as possible risk factor in rheumatoid arthritis and rheumatoid related osteoporosis. Hum Immunol 2014;75:452-61.

26. Sahebari M, Mirfeizi Z, Rezaieyazdi Z, Rafatpanah $\mathrm{H}$, Goshyeshi L. 25(OH) vitamin D serum values and rheumatoid arthritis disease activity (DA S28 ESR). Caspian J Intern Med 2014;5:148-55.

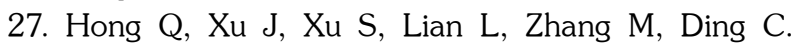
Associations between serum 25-hydroxyvitamin D and disease activity, inflammatory cytokines and bone loss in patients with rheumatoid arthritis. Rheumatology (Oxford) 2014;53:1994-2001. 